\title{
Performance Analysis of Isolated Hybrid Power Plant Model with Dynamic Load Conditions - Morning, Noon and Afternoon Transitions
}

\author{
Rina Irawati $^{*}$ \\ Research and Development Center for Electric ity, New, Renewable Energy, and Energy Conservation Technology - \\ Research and Development Agency of Ministry of Energy and Mineral Resources Republic of Indonesia, Jakarta - \\ Indonesia
}

\begin{abstract}
Diesel Generator with Photovoltaic Hybrid Power Plant is one of the solutions for supply electric demand to isolated area. The energy sources that can be used for hybrid system are such as photovoltaic, wind turbine, and biomass or biogas, because these sources are almost available in every isolated area. This research used a model of hybrid system from diesel generator and $1.28 \mathrm{kWp}$ photovoltaic power plant. The reliability and some of power quality of this system tested by 1300VA house hold daily load characteristic effectively 24 hour. Power quality and some electricity parameters during transition mode for each resource will be analyzed. Furthermore the power quality analyze will be conducted and evaluated base on Electrical Engineers' Association (EEA).
\end{abstract}

\section{Introduction}

Indonesia is an archipelagic country that has thousands of islands both populated and unpopulated. Along with the increasing of population, the need for electrical energy is also increasing. Most of the islands in Indonesia today still use diesel generator as electricity sources. With the high price of fuel oil, the price of electricity in the archipelago becomes very high. To reduce this dependence on fossil energy sources, it is necessary to develop a hybrid power plant system that combines diesel generators with electricity generated from renewable energy resources whose potential is in the area. So that the need for electric energy in isolated areas can be fulfilled with local potential energy sources.

Indonesia's geographical position crossed by the equator provides benefits for Indonesia, where renewable energy potential especially solar energy is very abundant because almost all regions in Indonesia can be exposed to the sun throughout the year. Nevertheless, electricity from solar energy does not necessarily directly replace electricity from fossil energy because the nature of renewable energy is generally intermittent depending on weather conditions. Therefore, the development of diesel generator hybrid system with solar power plant or Photovoltaic (PV) in archipelago areas is necessary[1].

The PV-Diesel hybrid system is potential to be developed in isolated islands but technical analysis in terms of the power of this system has not been done. Therefor we need to do research on the power quality of the PV-Diesel hybrid system.
This study aims to analyze the reliability and certain power quality parameters in an isolated PV-Diesel hybrid system, and provide an overview of the conditions that need to be anticipated on an isolated PVDiesel hybrid system to maintain the reliability and quality of electricity.

The scope of work in this research including:

a. The analysis was carried out on a laboratory-scale isolated PV-Diesel hybrid system with a load profile in accordance with the 1300 VA household customer's daily load curve.

b. The power quality standard used is the Power Quality Guidelines Electricity Engineers' Association.

c. The power quality parameters evaluated are relevant parameters and can be detected by the Fluke 435 Power Quality Analyzer and Sunny Webbox form SMA.

\section{Methodologies}

The research conducted base on literature study, observation and testing method. The performance analysis conducted to lab-scale PV-Diesel hybrid system model based on literatures and several scenarios. All electrical data connected to power quality observed and recorded during test. The power quality parameters then evaluated and compared with standard from Electrical Engineer's Association (EEA).

\footnotetext{
Corresponding author: rinairawatibm@gmail.com, rina.irawati@esdm.go.id
} 


\section{Literature Review}

A hybrid power system is a system consist of two or more power sources, operated simultaneously, including (but not necessarily) a storage system and connected to a local (mini/microgrid) network, equipped with a multifunction inverter to convert $\mathrm{DC}$ and $\mathrm{AC}$ power, regulate generation and storage, and adjust the voltage and frequency of the system. Local mini/micro grid can also be connected to a large grid or national grid, thereby increasing the reliability and power quality of the system[2].

The advantages of using renewable energy sources for generating power in remote islands are obvious such as the cost of transported fuel are often prohibitive fossil fuel and that there is increasing concern on the issues of climate change and global warming. The disadvantage of standalone power systems using renewable energy is that the availability of renewable energy sources has daily and seasonal patterns which results in difficulties in regulating the output power to cope with the load demand. Combining the renewable energy generation with conventional diesel power generation will enable the power generated from renewable energy sources to be more reliable and affordable. This kind of electric power generation system, which consists of renewable energy and fossil fuel generators together with an energy storage system and power conditioning system, is known as a hybrid power system[3].With a hybrid system, power quality problems from renewable energy sources can be overcome.

To know whether power quality of the system is god or not, its need to be tested refers to existing standard. One of the standards governing the quality of power is the standard Power Quality Guidelines issued by Electricity Engineers 'Association. The standards set by the EEA are as follows[4]:

1. Steady-state voltage: The test is performed by data retrieval interval at least every ten minutes.

2. Voltage dips/sags: trigger level is set to $90 \%$ of nominal voltage.

3. Swell voltage: trigger level is set $110 \%$ of nominal voltage

4. Harmonic voltage: testing is successful when $95 \%$ of data retrieval done at intervals every ten seconds does not cross the boundary.

5. Frequency: follow the IEC 61000-4-30 standardi.e. data retrieval at least every ten seconds. Therefore for data retrieval on the power meter is set every ten seconds.

Performance analysis is conducted on hybrid power generation system installed in Renewable Energy Integration Laboratory at Mochtar Riady Plaza Quantum, Department of Electrical Engineering Faculty of Engineering University of Indonesia. This system represents a microgrid with two power sources that supply home loads but has considerable flexibility for other test scenarios such as on-grid and off-grid. The test was performed with a daily load profile of R-1300 VA that was simulated using a Programmable AC Load Controller as seen on Fig. 1[1].

\section{Analysis}

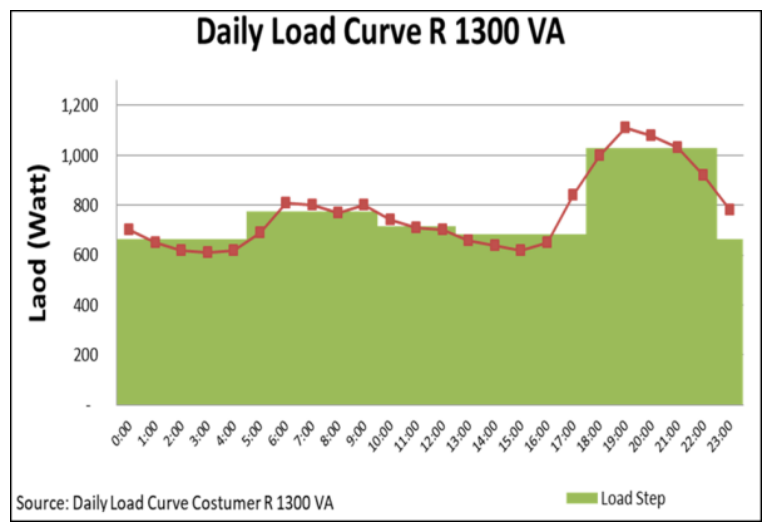

Fig. 1. Daily Load Profile.

The scheme in Fig. 2 is a simple representation of the installed test system. This system has two sources of electricity with one energy storage system. The first power source is a solar module whose output is converted into AC power and maximized with Maximum Power Point Tracker (MPPT) through Sunny Boy as a PV inverter and connected directly to the load and Sunny Island as a bidirectional inverter. The inverter $\mathrm{PV}$ output is connected to the bidirectional inverter and loads so when the energy production from PV larger then loads, PV inverter will supply the load and charges the batteries. However when the load power exceeds the power generated by PV, the load will be supplied by PV and batteries. The Bidirectional inverter itself is connected to an external power source in the form of a PLN grid or a diesel generator, and an energy storage system that is a battery bank. In the other hand, when the PV has no power output the PV inverter will detach from the system and the load will be supplied by the bidirectional inverter with the energy source of the battery. Then when the battery is within the specified State of Charge (SOC) limits, the diesel generator or PLN gird will supply the load and charge the battery through bidirectional inverter[1].

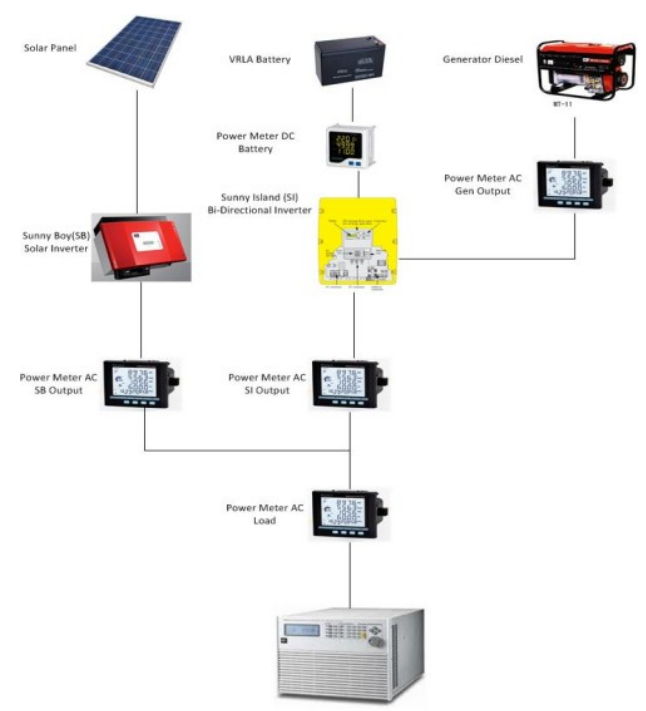

Fig. 2. Hybrid system test scheme. 
In this test system the load used is a programmable AC Load Chroma 63803 with a maximum load capacity of $3.5 \mathrm{~kW}$. The Power Factor value to be maintained is 0.9 lagging because the home load on the remote area is relatively linear load and if there is non-linear load it is inductive loads. Maximum current was set at 6 Ampere because the peak load is 1200 Watt which means current at system voltage 230 Volt is 5.2 Ampere.

In this study an analysis was conducted to the test results data along with the feasibility analysis of system power quality tested. The power quality parameters that are analyzed as follows:

- Steady-state voltage

- Harmonic voltage and Harmonic Flow

- Voltage dips / sags

- Swell voltage

- Frequency deviation

These parameters represent five of the eight power quality parameters found in the Electrical Engineer's Association (EEA) Power Quality Guideline. The power quality parameters analyzed are relevant to a low voltage (low voltage) test system and the availability of a measuring instrument that can measure the power quality parameters. The limits of these power quality parameters are as follows:

- Steady-state voltage: $\pm 6 \%$ of nominal voltage (216 Volts to 243.8 Volts for nominal voltage 230 Volt)

- Dip/sag voltage: $10 \%$ less than nominal voltage for a maximum of one minute (207 Volts for a nominal voltage of 230 Volts)

- Swell voltage: $10 \%$ more than nominal voltage for a maximum of one minute (253 Volts for a nominal voltage of 230 Volts).

- Harmonic voltage: maximum Voltage Total Harmonic Distortion is $8 \%$ for low voltage network

- Harmonic current: maximum Current Total Harmonic Distortion is 5\% for low voltage network with current ratio less than 20 .

- Frequency deviation: $\pm 1.5 \%$ of nominal voltage ( $49.25 \mathrm{~Hz}$ to $50.75 \mathrm{~Hz}$ for nominal frequency $50 \mathrm{~Hz}$ )

The evaluated parameters are measured in the same place i.e. Point of Evaluation (POE). POE in this system is Power Meter of Load. Power meter of load is selected as POE because it is the node closest to the load as can be seen in Fig. 2.

Analysis of power quality parameters is done on every circumstance and time so that we can understand more deeply the factors that cause the occurrence of a phenomenon or problem. The analysis is divided into six parts: Morning Transition, Noon, Afternoon Transition, Pre-Generator Night, Generator Night and PostGenerator Night.

Morning transition analysis is the analysis at 05.45 to 06.45. At this time the system supplies the load by using the battery even though the sun has shone until the inverter is able to supply the load to the system. This happens because the solar irradiation received by the solar cell does not produce enough voltage to initiate the inverter. We can verify when the inverter is on with bidirectional inverter Sunny Island data received in the Webbox. This means that in this analysis will be observed whether the initiation of inverters raises the problem of power quality on the system.

The noon analysis is the analysis at 08.00 to 14.30 . In this analysis the irradiation of the solar cell is high enough so that the solar cell charges the battery and supplies the load for most of the time in this analysis. When irradiation is down and the solar cell output power is not sufficient to supply the load and charge the battery, then battery bank will supply the load. In this analysis can be observed the effect of solar cell and irradiation on the power quality parameters tested.

The Afternoon transition analysis is an analysis from 16.45 to 18.00 . At 14.30 until 17.00 the sun is still shining but decreasing. At 17:00 until 18:00 solar irradiation is not enough to encourage solar cells to supply power to the system. Thus we can analyze the power quality parameters when the inverter changes the state of the supplying state until the inverter turns the operating status into deactivation.

The Pre-Generator night analysis is an analysis at 19.45 to 21.00 . At this time all load is supplied purely by the battery due to deactivated PV inverters and State of Charge (SOC) batteries that have not reached the lower limit to initiate the generator to work. Thus in this analysis we can analyze the effect of the battery on the power quality parameters tested.

The Generator night analysis is an analysis with test time from 21:00 to 00:00. In this analysis the battery that previously supplied the load will pass the lower limit of the SOC that can initiate the generator until the generator supplies the load and charges the battery. That means we can analyze the quality parameters tested from the moment of the generator starts syncing in order to supply power to the system until the system is already running with the generator as the main supply.

The Post-Generation night analysis is analysis at 00.00 to 05.45 . In the test period the batteries and loads previously supplied by the generator will be ordered to stop due to SOC batteries that have exceeded their upper limits. The data recorded in this analysis includes the post-stopping state of the generator system, this is so that we can analyze whether there is an effect when the generator is running that remains when the generator has stopped working. However, the main highlight of this analysis is the effect of transitions when the generator stops working.

Because each transition time has different effects on power quality, this paper will only cover morning, noon and afternoon transitions analysis. For night analysis, pre and post generators will be discussed in other papers.

\subsection{Morning Transition Analysis}

The morning transition analysis is intended to look deeper into the system condition when switching from the battery supply to PV supply due to the rising of solar irradiation. At 06:05 the status of the PV inverter changes to Waiting (Warten) which means the inverter is in Stand By condition waiting for the minimum voltage to supply the network achieved from the PV input. The status changes when the solar irradiation reaches the 
value of $9 \mathrm{~W} / \mathrm{m}^{2}$ to Mpp which means the inverter operates using MPPT to optimize the output power of the inverter. It should be noted that although the inverter is capable of exerting power but mostly still supplied by the battery, it can be seen in Fig. 3 where the battery SOC gradient still shows a negative value which means the battery is still decreasing.

Table 1. Webbox Data at 05:45-06:45

\begin{tabular}{rrrl}
\hline \multicolumn{1}{l}{ Time } & $\begin{array}{c}\text { Solar } \\
\text { Irradiation }\end{array}$ & $\begin{array}{c}\text { PV Inverter } \\
\text { Output Power } \\
\text { (Watt) }\end{array}$ & $\begin{array}{c}\text { PV } \\
\text { Inverter } \\
\text { Status }\end{array}$ \\
\hline $5: 45$ & 0.67 & & \\
$5: 50$ & 0.82 & & \\
$5: 55$ & 0.95 & & \\
$6: 00$ & 0.96 & 0 & $3:$ Warten \\
$6: 05$ & 3.15 & 0 & $3:$ Warten \\
$6: 10$ & 9 & 2.63 & $7:$ Mpp \\
$6: 15$ & 13.63 & 4.63 & $7: \mathrm{Mpp}$ \\
$6: 20$ & 21.48 & 10.88 & $7: \mathrm{Mpp}$ \\
$6: 25$ & 32.87 & 21.03 & $7: \mathrm{Mpp}$ \\
$6: 30$ & 44.77 & 30.03 & $7: \mathrm{Mpp}$ \\
$6: 35$ & 55.1 & 44.03 & $7: \mathrm{Mpp}$ \\
$6: 40$ & 73.07 & 75.03 & $7: \mathrm{Mpp}$ \\
$6: 45$ & 87.88 & 91.23 & $7: \mathrm{Mpp}$ \\
\hline
\end{tabular}

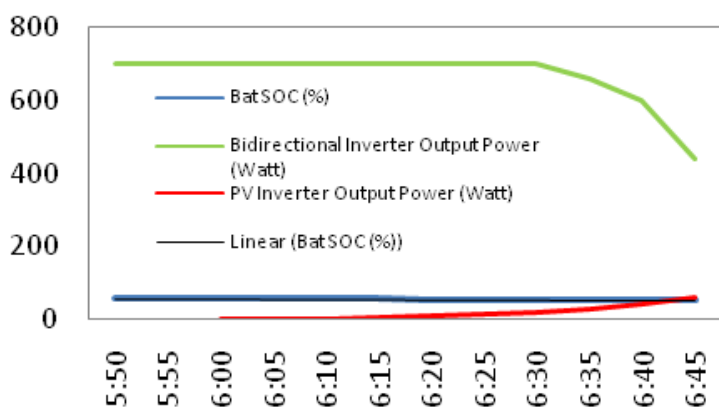

Fig. 3. Operation condition at 06:00 - 06:45

\subsubsection{Steady-state Voltage, Dips / Sags, Swell}

The active transition inverter does not seem to affect the voltage significantly. At 06:10 where the inverter status changed to Mpp the voltage increased only 0.2 Volt. The measured voltage has a range from the lowest 231.29 Volts to 231.58. With such a voltage range it can be concluded at this morning's transition the system is quite stable.

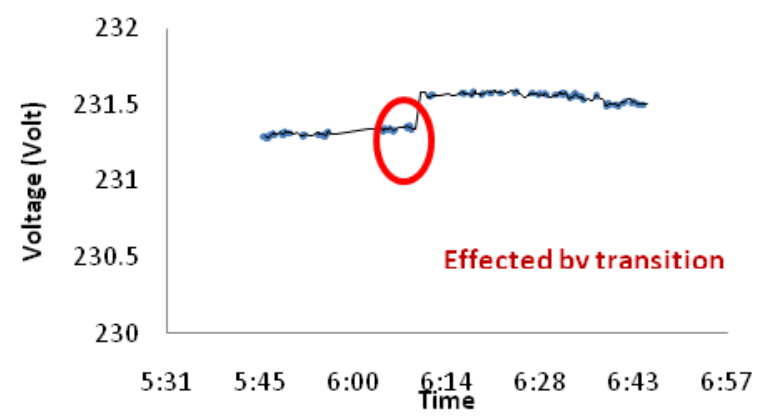

Fig. 4. Voltage at 05.00-06.45

\subsubsection{Voltage Harmonic}

The voltage harmonic at Fig. 5are seen to increase during the transition period. When the PV inverter Sunny Boy active voltage harmonic changed from $5.16 \%$ to $6.01 \%$. However when the power output of PV inverter Sunny Boy began to increase and reduce the output of Sunny Island voltage harmonics also decreased. The dynamics that occur in this PV inverter Sunny Boy is observed to affect the voltage harmonics but these parameters are still within the safe limits of power quality.

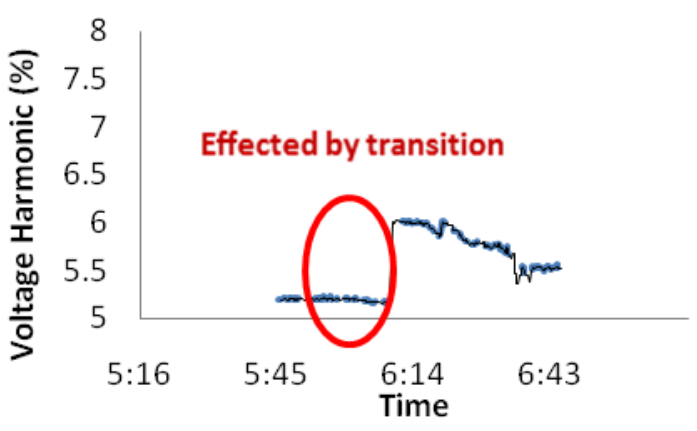

Fig. 5. Voltage harmonic at $05.45-06.45$

\subsubsection{Frequency Deviation}

The advent of the PV inverter as a new supply at observations at $05.45-06.45$ looks totally unaffected. The frequency remains stable until the end of the observation because the load and supply remain balanced. When the PV inverter Sunny Boy experiences increased power output bidirectional inverter Sunny Island can adjust well in reducing its output so that there is no overload or supply in the system.

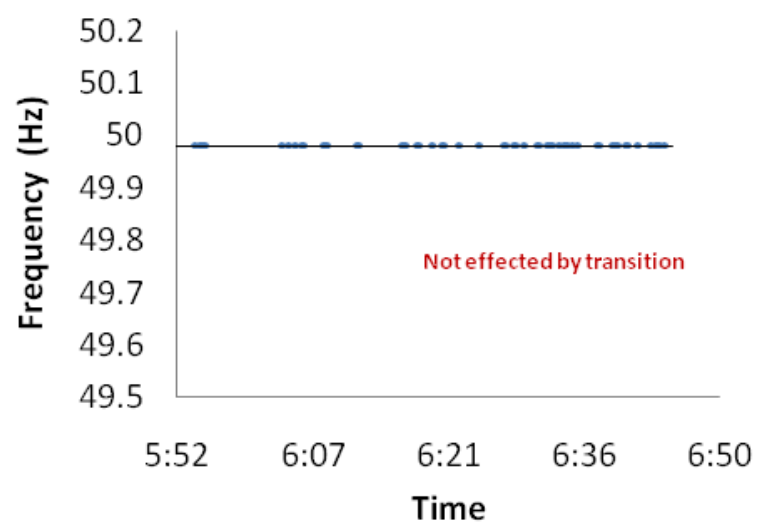

Fig. 6. Frequencies at $05.45-06.45$

\subsubsection{Current Harmonic}

In the current harmonic parameter there is no active inverter effect. The current harmonic in this analysis remain stable at a range of values of $54 \%$. The current harmonic parameters generally in the connected network 
are influenced by the load characteristics and in this experiment the load power is relatively fixed.

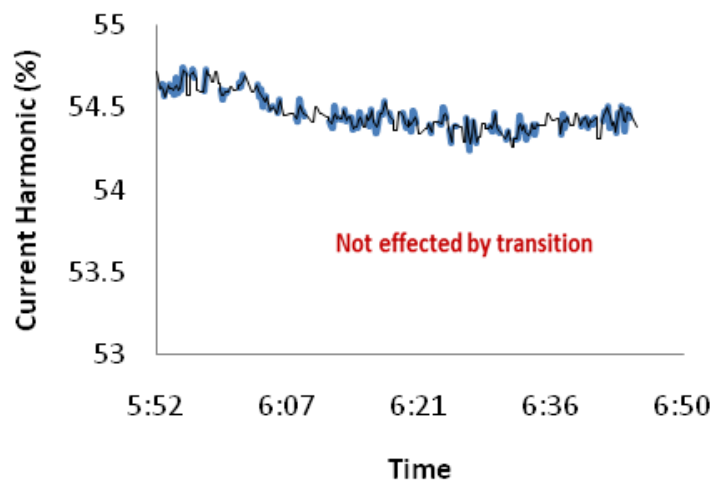

Fig. 7. Current Harmonic at 05:45-06.45

\subsubsection{Conclusion of Morning Transition Analysis}

From the data analysis above the active switching of the PV inverter Sunny Boy does not cause any meaningful problems either in terms of power quality or reliability but current harmonics are well over the limit. When the PV inverter Sunny Boy is active and starts supplying power to the system it only affects voltage and voltage harmonics with not really significant value. The frequency is not changed at all while the PV inverter Sunny Boy is active. The current harmonic parameters that should have a $5 \%$ limit on this analysis far exceed the limit to $54 \%$.

\subsection{Noon Analysis}

In this analysis the PV inverters already able to supply power into the load or charge a battery depends on solar irradiation. This can be seen in the graphic shown in Fig. 8 which is the result of footage at the time the system works during the day where during sun irradiation and Sunny Boy output is less than the load then Sunny Island which takes power from the battery helps to supply the load.

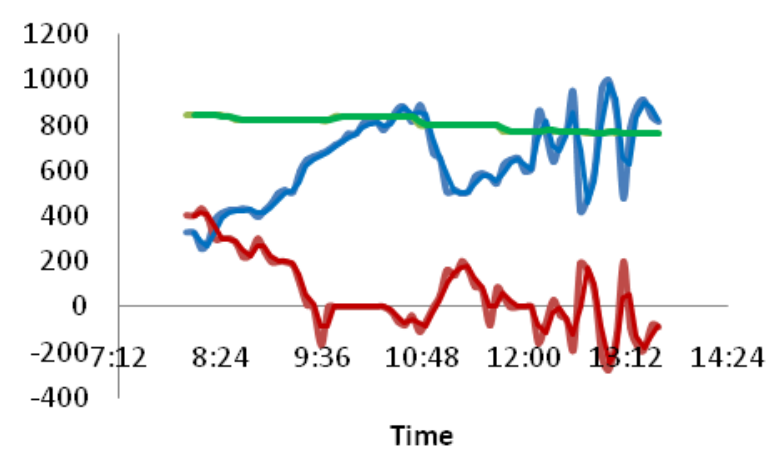

Fig. 8. Daylight System Characteristics

However, when the sun's irradiation and Sunny Boy's output is larger than the load, the Sunny Island output is negative, which means charging through Sunny Island. In order to understand in more detail in the next analysis it should be noted that the battery charging is done at $12: 10$ to $12: 35 ; 12: 55$ to 13.05 ; And 13.15 to 13.35 . At that time other than that time Sunny Island helped supply the load or output equal to zero.

\subsubsection{Steady-stateVoltage, Dips / Sags, Swell}

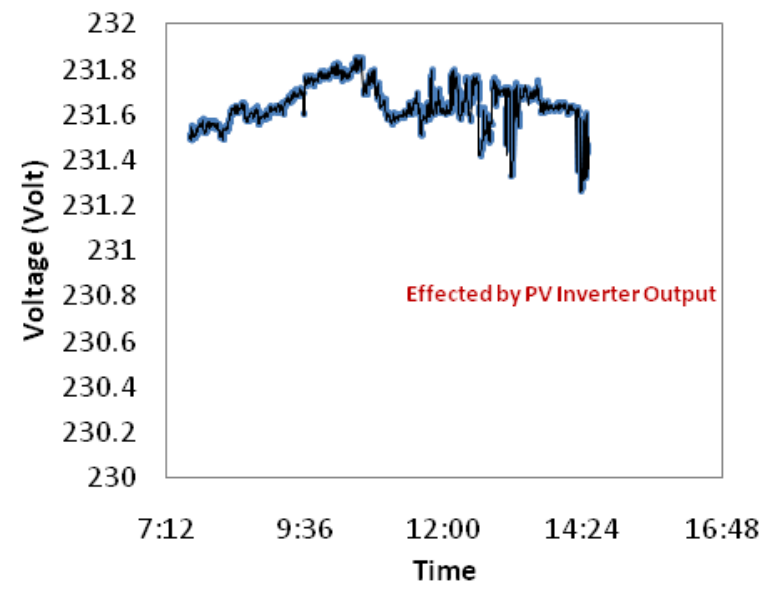

Fig. 9. Figure 11. Figure 4.8 System Voltages 08.00-14.30

The voltages in this analysis do not deviate too far and still within EEA standards. The system voltage should be 230 Volt but it rises up to the 231 Volt range. When compared to the voltage on the graph of Fig. 9, the sunny boy output, and the sun irradiation it can be seen that the ups and downs of the voltage follow the upward trend of sunny boy output and solar irradiation which means the system voltage is affected by the voltage supplied by the PV inverter. The highest voltage deviation is 231.85 around $10: 30$ and the lowest deviation is 231.25 at around 14:24.

\subsubsection{Voltage Harmonic}

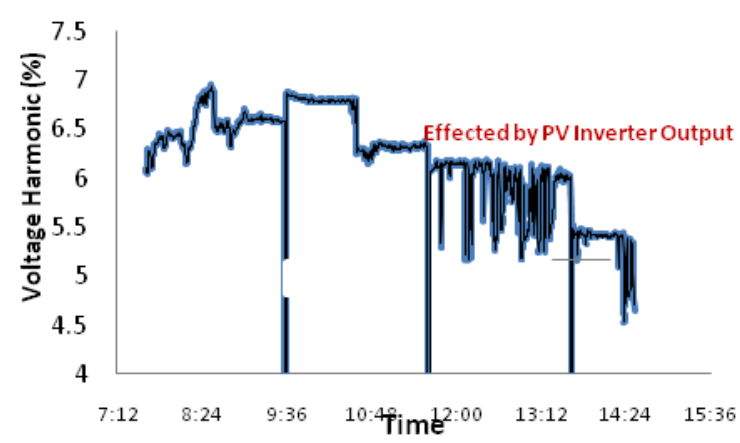

Fig. 10. Voltage Harmonic at 08.00-14.30

The voltage harmonics in this analysis do not exceed the $8 \%$ standard limit. The average voltage harmonic at this time period is in the range of $6 \%$. The highest voltage harmonic is $6.93 \%$ and the lowest is $4.62 \%$. The active components of the afternoon analysis are PV 
Inverter Sunny Boy, Bidirectional Inverter Sunny Island and battery while the system works on a power factor of 0.9 lagging. This means the voltage harmonics are generated with the greatest contribution of the inverter as well as the bidirectional inverter. Although the voltage harmonic generator is theoretically inverted but the resulting data trend of voltage harmonics has a gradient that is more comparable to the load and output of bidirectional inverter Sunny Island than the PV inverter Sunny Boy.

\subsubsection{Frequency Deviation}

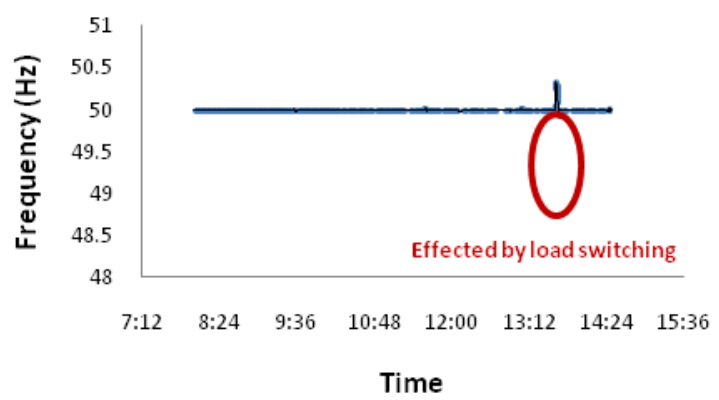

Fig. 11. Frequencies at $08.00-14.30$

Recorded frequencies indicate that day-to-day operating systems exhibit stable frequencies without significant frequency deviations and are within the standard range. The largest frequency deviation occurs at 13:38 which is $50.33 \mathrm{~Hz}$ while the smallest appears at 13.40 of 49.92 . Once traced, the cause of the frequency deviation between 13.38 and 13.40 is the instantaneous load change due to the load settings performed on the Programmable Load Chroma AC.

\subsubsection{Current Harmonic}

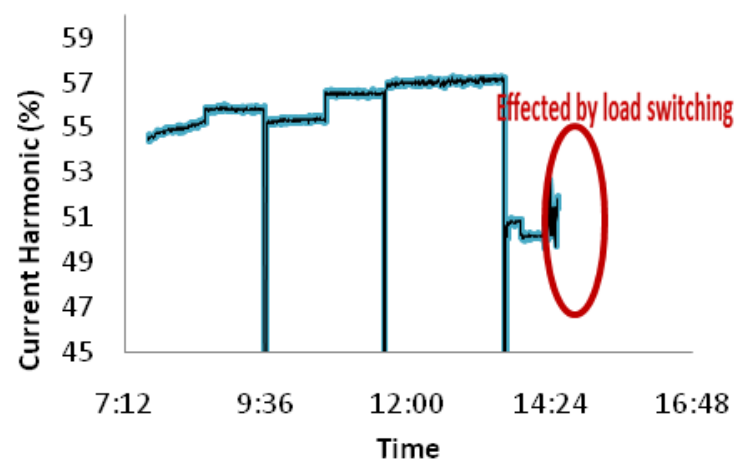

Fig. 12.Current harmonic at 08.00-14.30

The current harmonic at $08.00-14.30$ appears to be affected by system dynamics in the afternoon calibration experiments. The most obvious change is when the current harmonics decrease by more than $7 \%$ at 13.38 . These changes coincide with step load changes that are also down so this phenomenon becomes second evidence of harmonic currents in isolated tissue remains affected by the load. However, from 08:00 to 13:38 the harmonic currents tend to increase with the increase of the Sunny Boy inverter operation instead of the Sunny Island Inverter so that in this experiment it is seen that the current harmonics are affected not only by the load but also the Sunny Boy inverter.

\subsubsection{Conclusion of Noon Analysis}

In the noon analysis can be concluded that there is no problem of power quality or reliability other than the harmonic current parameters. Unobservable power quality limits are exceeded but note that voltage harmonics reach 6.93\% and the graph indicates the proportionality of voltage harmonics with allowable load power when during the day there are higher loads or larger Sunny Island inverter output can cause voltage harmonics to pass through limit. The harmonic flow once again passes the limit with a much higher value of up to $57.13 \%$. In terms of system reliability goes $100 \%$ without any trip at all.

\subsection{Afternoon Analysis}

From the Webbox data in Table 2 it can be observed how the system being tested operates affected by the start of sunset irradiation. At 16:45 to 17:00 where the lowest solar irradiation is $9.72 \mathrm{~W} / \mathrm{m}^{2}$ status Sunny Boy Inverter shows Mpp which means the inverter is working in MPPT mode. However in 17.05 the status of the inverter shows "Search-Mpp" (Mpp-Such).

Table 2. Webbox Data at16:45 to $18: 00$

\begin{tabular}{|c|c|c|c|c|}
\hline Time & $\begin{array}{c}\text { Solar } \\
\text { Irradiation } \\
\mathrm{W} / \mathrm{m}^{2}\end{array}$ & $\begin{array}{c}\text { Bidirectional } \\
\text { Inverter } \\
\text { Current } \\
\text { A } \\
\end{array}$ & $\begin{array}{c}\text { PV } \\
\text { Inverter } \\
\text { Power } \\
\text { W } \\
\end{array}$ & $\begin{array}{c}\mathrm{PV} \\
\text { Inverter } \\
\text { Status }\end{array}$ \\
\hline $16: 45$ & 17.03 & 3.26 & 11.53 & 7: Mpp \\
\hline $16: 50$ & 14.07 & 3.3 & 9.72 & 7: Mpp \\
\hline $16: 55$ & 11.6 & 3.3 & 6.77 & 7: Mpp \\
\hline $17: 00$ & 9.72 & 3.3 & 4.97 & 7: Mpp \\
\hline $17: 05$ & 8 & 3.37 & 2.56 & 6: Mpp-Such \\
\hline $17: 10$ & 6.14 & 3.32 & 0.04 & 2: Netzueb. \\
\hline $17: 15$ & 4.5 & 3.3 & 0 & 0 : Offset \\
\hline $17: 20$ & 2 & 2.37 & 0 & 3: Warten \\
\hline $17: 25$ & 1.08 & 3.3 & 0 & 3: Warten \\
\hline $17: 30$ & 1 & 3.3 & 0 & 3: Warten \\
\hline $17: 35$ & 1 & 3.3 & 0 & 3: Warten \\
\hline $17: 40$ & 1.08 & 3.3 & & \\
\hline $17: 45$ & 1 & 3.3 & & \\
\hline $17: 50$ & 1 & 3.3 & & \\
\hline $17: 55$ & 1 & 3.3 & & \\
\hline 18:00 & 1.1 & 3.3 & & \\
\hline
\end{tabular}

This means at that time the inverter is considering whether MPPT is still usable or not. At 17:15 the emerging status is off-set where in this state the inverter adjusts or arranges the measuring instrument to make it more sensitive to respond to smaller values. At 17:20 to 
17:35 Warten status appears or in the Indonesian language means wait, the intended wait here is the inverter in stand-by mode in some time until the minimum voltage to supply the network is reached. However, in the afternoon transition the most common is the minimum voltage will not be reached and the inverter will break away from the system or go into deactivation mode as seen in the table at 17.30 onwards.

\subsubsection{Steady-state Voltage, Dips / Sags And Swell}

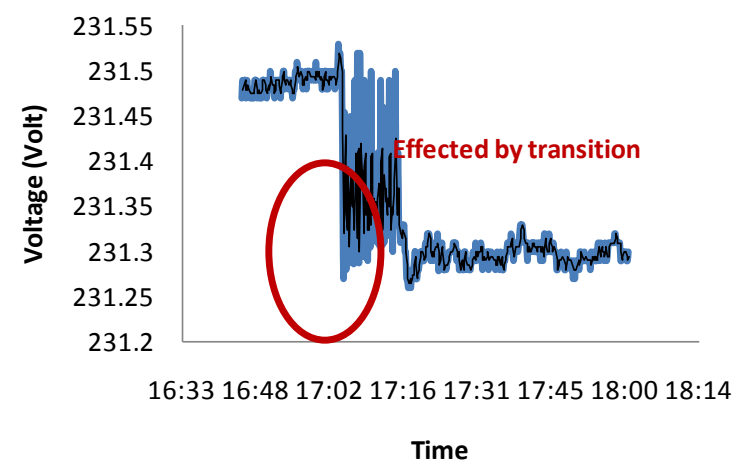

Fig. 13. System Voltages at $16: 45$ to $18: 00$

The system voltage at 16.45 to 18.00 is quite stable and is not far from its nominal voltage. The highest voltage observed at 17.03 is $231.5 \mathrm{~V}$ and the lowest is $231.26 \mathrm{~V}$ at 17.17 . Changing the voltage can be seen at 17.02 where the inverter has just changed from the status of mpp to 17.17 where the status of the inverter will turn into stand-by. This shows that the inverter's inactive transition affects the voltage but is not in an alarming state because it does not approach the limits of steadystate, dip or swell.

\subsubsection{Voltage Harmonic}

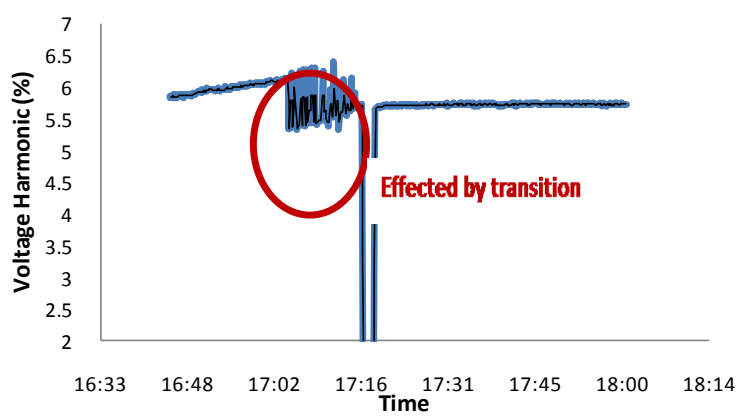

Fig. 14. Voltage Harmonic at 16:45 to 18:00

Harmonic stress in the analysis period that is analyzed is relatively stable with the harmonic quantity range is $5.8 \%$. The greatest harmonic is $6.39 \%$ at 17.10 and the lowest harmonic is $5.33 \%$ at 17.13 . In the evaluation of the voltage harmonic parameters it was observed that the value of this parameter varies when the inverter goes into its transitional period of inactivity but the effect of the transition is insignificant.

\subsubsection{Frequency Deviation}

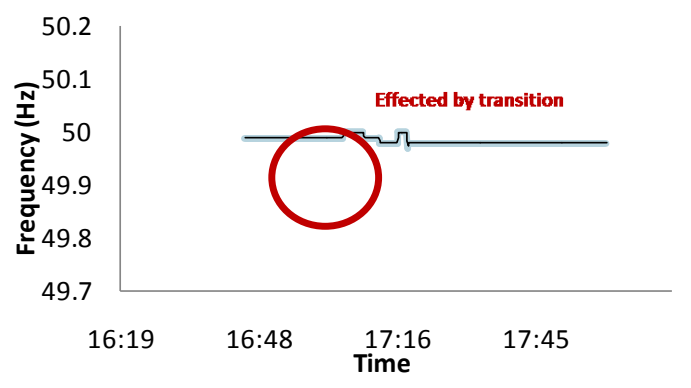

Fig. 15. System Frequencies at $16: 45$ to $18: 00$

The system frequency in this analysis ranges around $49.99 \mathrm{~Hz}$ and can be seen on the graph that the value is not exceeded and stable except at 17.02 to 17.16 . The lowest frequency value is at 17:19 which is 49.97 and the highest is $50 \mathrm{~Hz}$ at some time. The graph shows that the inverter's inactive transition greatly does not affect the frequency that only moves in the 2 numbers behind the comma.

\subsubsection{Current Harmonic}

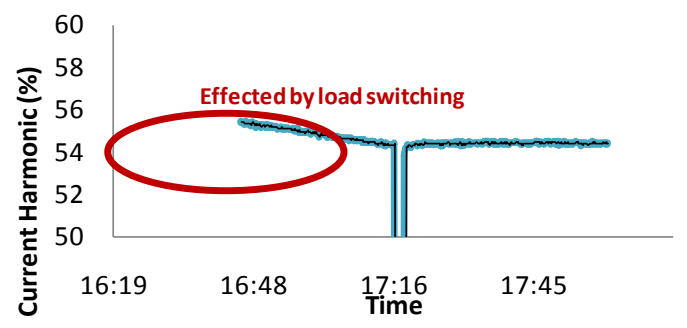

Fig. 16. Current Harmonic at 16.45-18.00

In the afternoon transition experiments the loads used are programmed to ensure the current harmonic trend against the load but only up to 17.17 . The programmed load is linearly decreasing and from the above graph it can be seen that the harmonic current follows the load which tends to decrease. Similar to the previous analysis the current harmonics cross the limit with a significant value that is above $54 \%$.

\subsubsection{Conclusion of Evening Transition Analysis}

In the analysis of Transition Evening analysis found that the transition of non-active inverter affect the parameters of power quality but not significant. The biggest effect of this transition is on the voltage harmonic where the transition period observed a shift of harmonic voltage value of $13.25 \%$ of harmonic voltage limits. Similar to the previous analysis the harmonic currents also exceed the limit of up to $55.34 \%$. In terms of reliability this 
transition does not lead to reduced reliability of the system in supplying the load.

\section{Conclusions}

From the analysis of research conducted to evaluate the reliability and some power quality parameters of isolated hybrid system in dynamic conditions, it can be concluded several things as follows. Power quality problems arise in several conditions:

1. The peak load voltage harmonic condition exceeds the standard.

2. The condition of the system with the harmonic generator supply exceeds the standard.

3. The post-inactive condition of the bi-directional generator inverter frequency exceeds the standard limit.

4. Specification of bi-directional inverter showing the voltage harmonic will not exceed 3\% not achieved.

The authors say thank you very much to Ryan Adilardy Prakoso and Brian Oscarino, undergraduates of Electrical Engineering UI, who have assisted authors in testing and retrieving data in the study of hybrid system at University of Indonesia Campus.

\section{References}

1. R. Irawati and E. A. Setiawan, “Analisis Keandalan Jaringan Listrik Mikro Cerdas Arus Bolak Balik Terisolasi," Makara Univ. Indones., pp. 1-19, 2014

2. G. Léna, Rural Electrification with PV Hybrid Systems, Juli 2013. IEA, 2013.
3. A. Setiawan and C. Nayar, "Design of Hybrid Power System for a Remote Island in Maldives," ... HOMER Webcast-NREL USA, pp. 1-5, 2006.

4. N. Watson, V. Gosbell, S. Perera, S. Elphick, and S. Hardie, Power Quality Guidelines, Rev 3.8., no. January. Wellington: Electricity Engineers' Association, 2013

5. PT PLN (Persero), Solar PV Development Plan. (2013).

6. Anwari, M. I. Hamid \& Makbul, Single-Phase Photovoltaic-Inverter Operation Characteristic in Distritibuted Generation System.. s.l.: InTech, Distributed Generation Vol. , (2010).

7. I. Muchsin, PUSAT PENGEMBANGAN BAHAN AJAR-UMB.Mesin Sinkron. s.l.

8. SMA Solar Technology AG.Sunny Boy 1200/1700 User Manual. Niestetal, Jerman : s.n.

9. Chroma ATE INC.,Programmable AC/DC Electronic Load 63800 Series Operation and Programming Manual. (2012).

10. Accuenergy,Acuvim II Series Power Meter User's Manual. (2012).

11. Endeavour Energy Power Quality \& Reliability Centre, University of Wollongong.Small Scale Domestic Rooftop Solar Photovoltaic System. (2011).

12. IEEE and IEC Harmonic Limits. Haplin, Mark.(2007).

13. SMA Solar Technology AG.Off-Grid Inverter Sunny Island 5048. 